International Journal of English Literature and Social Sciences
Vol-6, Issue-2; Mar-Apr, 2021
Journal Home Page Available: https://ijels.com/
Journal DOI: $10.22161 /$ ijels

\title{
Performers of Overlooked Spaces: A Critical Reading of Prajwal Parajuly's Short Stories, The Cleft and A Father's Journey
}

\author{
Lakshmypriya P P $\mathrm{P}^{1}$, Dr. N. Bhuvana ${ }^{2}$
}

${ }^{1}$ Research Scholar, Department of English, Providence College for Women, Coonoor, Affiliated to Bharathiar University, India ${ }^{2} \mathrm{Head}$, Department of English, Providence College for Women, Coonoor, Affiliated to Bharathiar University, India

Received: 03 Feb 2021; Received in revised form: 09 Mar 2021; Accepted: 04 Apr 2021; Available online: 28 Apr 2021

(C2021 The Author(s). Published by Infogain Publication. This is an open access article under the CC BY license

(https://creativecommons.org/licenses/by/4.0/).

\begin{abstract}
The study of space is not new and several critiques have done phenomenal work on it. One such scholar is Michel Foucault who has explained it in terms of six Heterotopias. These are spaces where norms of human behaviour remain suspended. Therefore, heterotopia is a physical representation or approximation of a utopia or a parallel space that contains undesirable factors making a real utopian space impossible. These spaces become a veritable stage where performers, irrespective of one's sex, construct and modulate space. Many studies have been conducted based on the Foucauldian spaces and their impact on human psyche but certain unconventional spaces like the trunk of a car, the interior of a widow's household have been overlooked. However, these spaces do exist and develop as a result of performance shown by people of different sexes and age.

This paper is an attempt to analyse such overlooked spaces which become vibrant due to the interplay of human behaviour. Most of the scholarly studies on the literatures of the North Eastern states of India and India's neighbouring countries like Nepal delve into history, culture, myths or politics, whereas the study of spaces has not been widely explored. Therefore, this paper focuses on the overlooked spaces which can be detected in the two short stories by a writer from Sikkim, a state from the North-Eastern part of India.
\end{abstract}

Keywords-Foucault, Heterotopia, Human performance, Nepal, North Eastern States, Space.

\section{INTRODUCTION}

The debutant work of Prajwal Parajuly, The Gurkha's Daughter was critically acclaimed for its candid representation of the Nepalese diaspora. Being the son of an Indian Nepali-speaking father and Nepalese mother and having spent a major part of his childhood in Gangtok, Sikkim, the culture, lifestyle and identity of the people of this area has deep impact on his writings. He is the first Indian to be offered a two-book multi-country deal by the London based publisher Quercus as a part of their project to bring out works on regional diaspora. The two short stories, titled The Cleft and A Father's Journey delve deep into the interiors of the Nepalese speaking household. In these two stories we find a very intricate interlink between spaces occupied by the characters that exerts tremendous thrust on the psyche of these characters. They take up roles and their performance changes the dynamics of the space that they occupy.

Living in a brave new world physical beauty does not matter but things are a little different for a poor servant girl living far off from home. A minor physical disparity like a cleft lip would cost her a lifespan of taunts, snide remarks and rude comments. The short story The Cleft provides a peek into the life of a thirteen year old girl named Kaali who lives with her rich widowed mistress Parvati in Kathmandu. On their way to Parvati's mother in law's funeral, Kaali, sitting in the trunk of the van, wishes to run away to become an actress. While sitting there she overhears conversation regarding her ugly appearance that shatters her dream, Parvati reveals her loneliness and the 
tender compassion she has for Kaali. Parvati's sister-inlaw Saritha at the same time reveals her wish to get a divorce and move abroad. The story deals with quest for freedom, companionship and truth not just for Kaali but for all the women in the story who unknowingly finds solace in each other.

When a child is born, a parent is also born is a common saying. The growth of a child is reflected in the character of the parent just like the life of the parent has its impact on the child. A Father's Journey takes us through a household in Gangtok where the life of the couple trapped in a loveless marriage revolves around their only daughter. When Prabin, the father, realises the impact of a silly thing that he told his daughter Supriya when she was hardly six, he feels flabbergasted by the effect he has on his child. He finds redemption when he makes Supriya realise that all Brahmins are not good prospective grooms; in the same way he made her understand that not all Bengalis are wise and not all girls are silly during her childhood.

\section{REVIEW OF LITERATURE}

Through these stories, Parajuly makes the reader identify with the space of his characters and its effects on their daily lives and behaviour. By referring to Michel Foucault's principle of space as heterotopias, that are real physical or mental spaces which exists, a viable study of the overlooked spaces will provide a different perspective of the select short stories. Foucault at the same time has defied Judith Butler's idea of performity based on sexuality and sexual identity. Foucault turned back to ancient thoughts to insist that one need not posit a subject and sexuality behind action. He states that external factors like space can also affect the gender performity and roles.

Theories are different looking glasses through which the society can be analysed. In order to deconstruct the space of the characters in the short stories, the looking glass of Foucault's idea of space can be deployed. French philosopher Michel Foucault explains the impact of the spaces through his Theory of Heterotopia and he enumerates six types of heterotopia; each having special purposes and characteristics. The Heterotopia of Crisis is a space reserved for individuals who are, in relation to society and to the human environment in which they live, in a state of crisis like a hostel or a menstruation home. Heterotopia of Deviation is the institution where individuals whose behaviour is outside the norm are placed like a jail or a mental asylum. The next type is the Heterotopia where a single real place juxtaposes several spaces like a garden where plants from several parts of the world are grown. Heterotopia of Time encloses in one place objects from all times and styles like a museum or a library. Heterotopia of Ritual or Purification refers to spaces that are isolated and penetrable yet not freely accessible like a movie theatre which is a public place but accessible only through a ritual like submitting a ticket at the entrance. The final Heterotopia encompasses the function of Illusion and Compensation. Heterotopia of Illusion creates a space of illusion that exposes every real space, and the Heterotopia of Compensation creates a space that is a compensation for a real space like a cemetery. Foucault also mentions 'the ship' which is a perfect or ideal heterotopia where there is no power play.

These are actual spaces where norms of human behaviour remains suspended. These spaces are created and recreated according to human behaviour, laws and needs. Foucault while discussing the relevance of heterotopic spaces in the psyche of human beings in his work The Order of Things says that "We do not live in a homogenous and empty space. ... The space in which we live, which draws us out of ourselves, in which the erosion of our lives, our time and our history occurs, the space that claws and gnaws at us, is also, in itself, a heterogeneous space" (3).

Etymologically the word came from the Greek terms 'hetero' meaning other and 'topia' meaning space; thus the word Heterotopia means 'other space'. So one can say, heterotopia is a physical representation or approximation of a utopia or a parallel space that makes a real utopian space impossible. Foucault identifies six different types of Heterotopic spaces, each having special purposes and characteristics. Each of these spaces affects the human psyche in a different manner. A single space could come under any of the six Heterotopic spaces depending on the people as it varies according to culture, geographical area and emotional state of a person.

Heba M. Sharobeem while discussing the effect of Heterotopic spaces in the tribal population in the work Space as the Representation of Cultural Conflict and Gender Relations in Chimamanda Ngozi Adichie's "The Thing Around Your Neck" states that "the space in which one lives, which draws us out of ourselves, in which the erosion of our lives, our time and our history occurs, the space that claws and gnaws at us, is also, in itself, a Heterotopic space"(2).

\section{EFFECTS OF HETEROTOPIA ON OVERLOOKED SPACES}

From these cases one comes to the understanding that many scholarly works have been carried out in relation to the Foucauldian idea of space. However, no source is found on any Foucauldian spatial study done on 
Parajuly's short stories and on gender performativity of people in relation to the overlooked spaces.

Parajuly's stories are different because of his illustration of the overlooked spaces such as a widow's household, the area occupied by a servant girl, the trunk of a car and the home of a couple trapped in a loveless marriage. More attention is paid on such areas and their effects on the marginalised people of North-Eastern part of India and the Nepal region. Like the land and people of the North-Eastern part of India and the neighbouring area of Nepal, the literary works of these areas are also largely unexplored.

Prajwal Parajuly's stories have their roots deep into the Nepali speaking soil. Applying Foucault's theory of Heterotopia, the paper aims to elucidate such spaces which exist and exert tremendous influence on the psyche of the people. Both the short stories The Cleft and $A$ Father's Journey account for many different Heterotopias.

In the short story The Cleft Kaali, the thirteen year old servant girl was unwelcome even in her own family and her mother sold her when she was just eight. Naming the child 'Kaali- the black one' itself shows how the dark child with cleft lips was not accepted by her own family. But the widowed Parvati kept Kaali with her in her house in Kathmandu. She was kept away from the usual circumstances of an Indian girl because of her biological deformity of having the cleft lips and the widow Parvati's home thus acts as a Heterotopia of Crisis for her.

The girl finds access to the space of Parvati's household because of her uncomplaining, submissive attitude. The widow's house can thus be considered as a heterotopic space that requires a gesture, ticket or some ritual for entering. It is Kaali's demure, submissive nature that acts as her ticket to Parvati's home. Heterotopic spaces also have the precise function of reflecting on the society that they exist in. In the story the space reflects on the practices happening in the society which sells children for money because of poverty as well as prejudices. It also reflects on the child-labour, which is unashamedly practiced even in modern times, in the Indian subcontinent.

In the story, after a phone call with Saritha, her sister-in-law, Parvati bursts out saying, "Of course, you are, you fool. I don't know who else is going to fill up the van. No space? She'll probably bring that Australian paying guest she takes everywhere with her - that elephant. You can sit in the trunk. After all, I'm paying two thousand rupees. What are the others paying then? Nothing!" (Parajuly 8). When they made arrangements to go to Birtamod in Nepal to attend the funeral of Parvati's mother in law, Saritha asks Parvati to pay two thousand rupees for the transportation. She being an outsider, it is
Parvati's ticket or gesture to enter the heterotopic space of the van of Saritha's household. Kaali being her servant is given access to sit in the trunk as Parvati is her ticket to this Heterotopic space. This also reflects on the hypocritical social norms that keep the daughter-in-law as an outsider.

Kaali rejoices as she is allowed to go with them. As Kaali is just a servant, she is made to sit in the trunk of the van, thus making the trunk a heterotopia of deviance. When they enter the van, Kaali though made to sit in the trunk of the van, finds it to be the most comfortable space as she enjoys more room there than the people in the front. She also gets to listen to the conversations without the others knowing that she is listening. This way the trunk no more remains the heterotopia of deviance. Foucault defines the perfect heterotopia as a ship where everyone is happy and equal. When Kaali has a comfortable place to sit and has the opportunity to listen to the conversations of Parvati and Saritha, she enters the perfect heterotopia which is often called as the 'Foucauldian ship'.

Saritha explains the presence of Erin, her foreigner tenant, in the van as "She's a paying guest. She's been with me for a month. After the news of Aamaa's death today, she told me she'd be my mother from now on. I call her Aamaa, and she likes it. She wanted to see a proper Nepali funeral, so I told her to come along" (Parajuly 13). Erin, the Australian woman had access to the heterotopic space of the van because of a different reason which is the affection Saritha has for her. Like Parvati is Kaali's ticket to that space, Saritha is Erin's. Heterotopic spaces have the power to juxtapose several real places and emplacements simultaneously. Erin's presence and the Australian identity is juxtaposed with the Indian identity of the space and the difference is clearly seen in Saritha's attitude and thoughts because of this European influence.

Erin clicks photographs of the places they pass freezing time in her frames. Heterotopic spaces are linked slices of time and truly work when people are given a break from the traditional time. By clicking pictures of the different places they pass through, she creates an archive of the landscape of the Indian subcontinent, thus encompassing time in the Heterotopic space of the Van, later on to be taken with her to her homeland.

Kaali acquires money from a certain person to go to India, which acts as her ticket to enter the Heterotopic space. Throughout the story, Kaali snaps in and out of a mental space where a male, who poses as a friend, keeps persuading her to run away from her mistress and become a Bollywood star. But by the end of the journey, she realises that her friend was misleading her and she would 
end up probably in a brothel if she followed his advice. So she snaps out of that space and decides to stay in the heterotopia of her mistress' home.

Heterotopic spaces like these have serious impacts on the gender roles and performances of the people involved. Parvati, in a usual Nepali household would be expected to be submissive and demure as she is the daughter-in-law. But after her husband's death, her home becomes a space where she is the dominant person despite her widowhood. Gender performativity is affected and modulated by space this way in her case. Similarly, Kaali as she enters the heterotopia of the trunk of the van, which is the 'Foucauldian ship', gains a sense of equality and freedom which results in her taking a decision for herself and not follow the lead of the man who was dictating her to run away. Even Saritha gets influenced by the space when Erin, the strong independent Australian woman, enters it and the former decides to get a divorce and go abroad.

Like the elements of Heterotopia in the short story The Cleft, elements of Heterotopia can be seen in the short story A Father's Journey too.

In this short story, Parajuly take the reader into the private space of a house in Gangtok. The father Prabin owns a successful bookstore in the main market of Gangtok. The bookstore is a Heterotopic space as time can be accumulated and frozen there like in a library or museum.

When one looks into the household, one can find a routine: "After dinner, Supriya and Prabin headed up the terrace and through the narrow spiral staircase into the make-shift crow's nest - a semi constructed room with French windows, a yet-unpaved floor and two chairs - to savour half an hour's view of Gangtok before darkness swallowed it." (65). This is Prabin's private abode. It has two chairs and Prabin takes Supriya to enjoy the view while Khusboo his wife is never invited. In a normal household such a private space would be shared by the couple rather than the father and daughter. It is because of the constraints in their marriage, Khusboo is never invited to that space. Prabin had actually constructed the crow's nest to stay away from his wife. Thus Prabin's affection is the ticket to the Heterotopia of the crow's nest.

Supriya and Prabin thus shared a special bond. When she was a child, he always took her to school, made her laugh and cuddled with her at night telling stories. But few years later their chemistry altered. "The snuggle routine, which started with Supriya's heading from her bed and jumping into his earl in the morning, had stopped a year ago, heralding a new phase in their relationship. The hugs, kisses and easy physical comforts graduated to high- fives, thumbs-ups and a special awareness that Prabin hadn't quite noticed evolved." (73)

The psychological and the social growth of the child had its impact on their relationship. As Supriya grew, she comes in terms with the society that does not allow a father and daughter to be close even though their intentions are platonic. The Heterotopia of Crisis can be seen as the adolescent finds a different space as she grows biologically because of the societal norms.

When Supriya menstruated for the first time, her mother kept her in a separate room for seven days. When Prabin asked her the reason for her cross behaviour that followed, she lashes out at him and tells:

You locked me in a room for seven days. Mua told me that I couldn't see the sun, that I couldn't see a man's face. All those days there, I cried. I cried because I felt guilty, because I thought I had committed a sin. I'd look at myself in the mirror and hate myself. I honestly thought I was an evil person, or that I had done something bad. My body hurt and so did my thoughts. When I confided in a teacher at school, she said I might have been depressed. Seven days in a room, bua.

The room that Supriya was kept in for seven days can be taken as an example of Heterotopia of Crisis which is privileged, sacred or forbidden spaces reserved for individuals who are in relation to the society in crisis. It was a space of isolation for Supriya even though the society considered this space to be sacred. For her it was a Heterotopia of Deviation as she felt entrapped in this particular space. She felt like she was punished for doing a crime or kept hidden for shaming the family. She felt guilty, dirty and depressed showing how the Heterotopia affected her psyche. Her relationship with Prabin soured because she felt betrayed as he didn't save her from the isolation of the room. It took several years for the relationship to go back to the earlier state emphasising on the effect of Heterotopic spaces on human relations and power structures.

In this short story also space plays a pivotal role in modulating and affecting the gender roles and performance. When little Supriya enters the heterotopic space of the society that does not allow a father and daughter to be close, she starts moving away from her father. Prabin being part of the society, gets agitated as his daughter confines herself to the societal gender roles. As Supriya grew the society influences their Foucauldian ship affecting their relationship and the performance of the individuals. Khusboo, the mother who should be an integral part of the family is neglected and made a part of 
just the background of the main picture. This is the reason why she is not included into the crow's nest or space which is shared by the father and daughter. This space is symbolic of their whole family dynamic affecting Khusboo's performance and forcing her to find satisfaction in just being a doting mother.

\section{CONCLUSION}

The study of Heterotopia in these short stories The Cleft and A Father's Journey, deal with the spaces that are usually overlooked or considered ordinary. Space influences the psyche in such a way that the power structure gets defined accordingly and gender roles are signified. It also helps in analysing the psyche of the people who when entering such spaces are influenced by its structure. The attitude of the society especially towards women, children and the specially-abled is witnessed in the above stories. The study of the spaces also brings to light the economic condition of the people especially the division between the rich and the poor as that division is crucial in the individual's entry into several Heterotopic spaces.

The application of the Foucauldian theory of Heterotopia to the short stories shows the conventional concept of space being deconstructed. The focus has been shifted from the prominent spaces to the overlooked spaces and the analysis is done based on the potential and influence of these spaces on the characters. There is a decentring of the idea of space leading to a new outlook in the genre. This helps in providing a different view point in the study of gendering identities and even the interlink between power structures.

The paper also guides future scholars to delve deeper into the study of the various spaces. It also introduces them to the literatures of the North-Eastern states of India which is an upcoming modern literary arena. The stories in the text have special detailing to make the readers understand, identify and appreciate a community as Parajuly feels that the people in the Indian subcontinent are indifferent to a particular group of people. Thus the study paves way for future scholars to apply the theory into indigenous literatures making them part of the mainstream scholarly endeavours.

\section{REFERENCES}

[1] Colebrook, C. (2004). Gender. Palgrave Macmillan.

[2] Foucault, M. (1970). The Order of Things: An Archaeology of Human Sciences. Pantheon Books.

[3] Heterotopia (Space). (2020, December 4) In Wikipedia. https://en.wikipedia.org/w/index.php?title=Heterotopia_(sp ace)\&action=history.
[4] Parajuly, P. (2012). The Gurkha's Daughter. Quercus.

[5] Raffnsøe, S. (2017). The Foucault Effect in Organization Studies. Organization Studies, 40(2), 155-182. Retrieved from http://www.doi.org/10.1177.0170840617745110.

[6] Sharobeem, H. (2014). Space as the Representation of Cultural Conflict and Gender Relations in Chimamanda Ngozi Adichie's The Thing Around Your Neck. Rocky Mountain Modern Language Association, 69(1), 1826.Retrieved from www.jsor.org/stable/24372861.

[7] Shah, R. (2014). Urban Panopticism and Heterotopic Space in Kafka's Der Process and Orwell's Nineteen Eighty-Four. Wayne State University Press, 56(4), 701-723. Retrieved from https://www.jstor.org/stable/10.13110/criticism.56.4.0701.

[8] Wrede, T. (2015). Space and Gender in the 21st Century. Rocky Mountain Modern Language Association, 69(1), 1017. Retrieved from www.jstor.org/stable/24372860. 